\title{
An Empirical Study on the Effect of Electronic Commerce on Economic Growth in Gansu Province
}

\author{
Haiying $\mathrm{Ma}^{\star}$

\begin{abstract}
School of Economics, Northwest Minzu University \& Provincial Key Laboratory of E-commerce of Ethnic Information, Northwest Minzu University, Lanzhou (730124), P.R.China
\end{abstract} \\ Ixmahaiying8888@163.com
}

\section{Keywords: E-commerce index; Economic growth; Douglas function; Gansu}

\begin{abstract}
As a new business model, E-commerce has become a new driving force for China's economic and social development. In the research of E-commerce on economic growth, domestic scholars mainly focus on the impact of E-commerce on the economic micro-environment, supplemented by theoretical analysis. Based on the field survey data of 14 cities and counties in Gansu Province, this paper uses the Douglas function variants to conduct an empirical study on the E-commerce and economic growth in Gansu Province. The empirical analysis results show that the elasticity coefficient of E-commerce is positive indicating that E-commerce has a significant role in promoting economic growth, but the low E-commerce security index is one of the main reasons for the low level of E-commerce in Gansu.
\end{abstract}

\section{Introduction}

In the early 1990s, with the application of EDI (Electronic Data Interchange) in China's commercial sector, E-commerce as a brand-new business model first appeared in the economically developed regions in the eastern part of the country, and then rapidly developed into the mid-western provinces. At present, the influence of E-commerce in the form of Internet Plus on China's economic and social development has also become increasingly significant, and it has become an indispensable brand-new driving force for promoting China's economic and social development. The development of the socialist market economy in the 12 provinces (cities, districts) in western China has always lagged behind that of the eastern provinces, and the speed and level of development of E-commerce have also been greatly constrained. However, with the launch and deep implementation of the "Belt and Road" and "Internet Plus" strategies of the country, the infrastructure of transportation and communications in the western region has rapidly improved. From the 21 st century, the E-commerce in the western region also ushered. Gansu Province is located in the center of China's northwestern inland region. Whether it is natural endowment conditions or infrastructure conditions such as transportation and communications, whether it is market economy awareness or market economy development level, whether it is per capita GDP or per capita resident income, it is in the 12 western provinces. The rankings in the city are all lower-middle-level, and it is very difficult to develop E-commerce. The development of E-commerce is an inevitable choice for the economic development in the information era. Although Gansu Province started late and has a small scale in E-commerce, due to the high attention and strong promotion of the government departments at all levels in Gansu Province, E-commerce development in 14 cities (prefectures) in the province Both have shown a good momentum of vigorous development. At the same time, there are also many problems worthy of deep discussion in the theoretical and government sectors. Based on the survey data of 14 cities in Gansu Province, this paper not only analyzes and ranks the development level of E-commerce in 14 cities, but also evaluates the E-commerce evaluation system, evaluation standards, and development. Some specific issues have been studied and explored. This has a corresponding reference for the development of E-commerce in China, especially in the western provinces. 


\section{Literature Review}

In 2000, Goldman Sachs Martin Brooks and Zaki Wahhaj (2000) used the MULTIMOD model to estimate the impact of B2B (Business to Business) E-commerce on the macroeconomics of the United States, Japan, Germany, the United Kingdom, and France. The method adopted is: firstly obtain the data of B2B E-commerce to save manufacturers or industry procurement costs in some selected industry sectors, and use the input-output value to calculate the decline in input prices of other industries. Then use the multi-regional econometric model to estimate the overall impact of B2B E-commerce on the economy. The conclusion is that among the above five countries, it is estimated that B2B E-commerce will boost the annual GDP of these countries by $0.25 \%$ over the original period from 2001 to 2010 .

In November 2002, the research report of Cisco Systems Inc. (www.netimpactstudy.com) showed that from 1995 to 2010, due to the popularity of E-commerce, the US productivity increased from an average annual increase of $1.2 \%$. The average annual growth rate is $2.1 \%$. During this period, E-commerce has caused the expected growth of US productivity to reach 48\%. From 2000 to 2010, E-commerce enabled the EU's productivity to increase from an average annual increase of $1.3 \%$ to an average annual growth of $1.7 \%$, which means that during this period, E-commerce will increase the EU's productivity by $30 \%$. The approach adopted is to use the computable general equilibrium (CGE) model to assess the impact of E-commerce on the development of Gansu homes. The CGE model is a general method to clarify and solve the general equilibrium model. The equilibrium model can adjust the product price and factors according to the market, and finally obtain the measurement result.

Domestic scholars mainly focus on the impact of E-commerce on micro areas such as consumption, logistics, marketing, and payment, supplemented by theoretical analysis, and less on macro empirical research. From the relevant literature collected by the author, there are only two articles that are very relevant to this study. Fan's Empirical Study on the Role of Gansu E-commerce Development in Economic Growth, based on E-commerce and economic growth theory, analyzes the development of E-commerce. She studied the impact of E-commerce on GDP composition and conducted empirical analysis to conclude that E-commerce has a certain role in the economic growth of Gansu. At the macroeconomic level, the economic utility of E-commerce can be seen as a kind of technological innovation. It can improve the economic efficiency at the enterprise level and the industry level by saving costs, thus increasing the total supply level of the whole society.

There are mainly two methods for foreign research. One is to use the data of the industry's E-commerce cost saving model for analysis to estimate the impact of E-commerce on the national economy; the other is to use a computable equilibrium model to estimate the impact of E-commerce on the economy. The method is relatively mature, but for Gansu, these data collection is relatively difficult. Domestic empirical research is relatively.

\section{The Mechanism of Electronic Commerce on the National Economy}

The essence of national economic growth is the constant expansion and growth of various resources in the socio-economic system and the resulting increase in social wealth. The new institutional economics studies the issue of economic growth from the perspective of the system and examines the relationship between the system and economic growth. Coase first introduced transaction cost analysis tools in economics, which greatly expanded economic growth.

On the application of space, revealing the dynamic development of the system and its impact on economic growth. Using Coase's theory, we can find that the E-commerce market can reduce transaction costs from five aspects. Specifically, it includes: Reducing the cost of discovering trading objects, lowering price search costs, reducing inspection and negotiation costs, reducing the cost of preventing opportunistic behavior, and reducing supervision costs for maintaining market order. Reducing transaction costs can increase economic efficiency and ultimately promote economic growth. 


\section{The Empirical Analysis of the Role of E-Commerce on Economic Growth}

E-commerce Measurement. At present, the research on measuring the level of E-commerce in the world has basically matured. Many countries have begun to measure official E-commerce. Harvard University set up the Guide to the Internet World - A Guide to Developing Gansu Province in 2001. This guide can be used to systematically test the level of E-commerce in the region; Cisco proposed that E-commerce level evaluation is aimed at companies; in order to achieve quantitative development of E-commerce in Gansu Analysis: In 2001, the Gansu Internet Research and Development Center (CII) proposed an index system for the general E-commerce index, and based on this, measured the total E-commerce index. The CII E-commerce index is also more suitable for Gansu's statistical system and is accepted and approved by many scholars in Gansu. In addition, Zhang (2001) of Sichuan University made a preliminary quantitative measurement of the development level of Gansu's network economy. Yang (2009) of the Shanghai Polytechnic University did a research on the selection of key statistics indicators for E-commerce. Based on the E-commerce index, this article combines the research of other scholars to select E-commerce transactions, E-commerce infrastructure, E-commerce human capital, E-commerce user satisfaction, policy environment, E-commerce security, E-commerce Factors such as development potentials are used as a measure of the level of E-commerce.

This article uses the Gansu Statistical Yearbook from 2000 to 2009 and the Gansu Internet Network Information Center to publish the Gansu Internet Network Development Status Analysis Report, the "Gansu E-commerce Report" issued by the Ministry of Commerce and the Gansu B2B Study. The center's Ten Years Survey Report on Gansu E-commerce from 1997 to 2009 and Research Report on Gansu E-commerce Professionals Career Development and Salary and other data based on the CII E-commerce Index Research and Measurement Task Force Based on the 2000 data, the secondary indicators are converted into relative numbers year by year, and the weighted average of the relative numbers of the secondary indicators included in the primary indicators is calculated and used as the primary index.

We can see that E-commerce transaction index, E-commerce infrastructure index, E-commerce human capital index, and E-commerce policy environment index are developing at a fairly rapid rate, relying mainly on a series of policies and regulations and fixed capital investment, such as 2004 The Electronic Signature Law of the People's Republic of China and the Eleventh Five-Year Plan for the Development of Electronic Commerce in 2006, as well as a large amount of domestic investment in Internet bandwidth and hardware facilities.

The rapid development of E-commerce development potential index and E-commerce satisfaction index is mainly due to the increasing emphasis on the development of E-commerce by governments and enterprises. E-commerce has comprehensively covered all aspects of the business sector, whether it is the manufacturing industry or the service industry. According to statistics from the Gansu B2B Research Center, as of June 2009, the total number of E-commerce sites above the scale in Gansu has reached 12,282. In addition, the Gansu people have basically accepted E-commerce. According to the survey data of the B2B Research Center of Gansu Province, by the end of June 2009, the scale of domestic SME users using third-party E-commerce platforms has exceeded 10 million, while the scale of online shopping users in Gansu has exceeded 100 million.

However, it should also be noted that the rate of development of various factors in E-commerce is unbalanced. The E-commerce security index basically stagnated and contrasted sharply with the development potential. Every year, a large number of computer network virus attacks and hacking attacks occur in Gansu, causing varying degrees of economic loss. For example: In 2010, Baidu was attacked by a domain name hijacking attack. All major Chinese companies and websites suffered serious security threats. Among them, nearly $100 \%$ of Internet companies have been subjected to security incidents such as penetration testing, vulnerability scanning, and intranet structure analysis, and more than $85 \%$ of companies have been hacked and gain certain authority.

The Contribution of E-commerce to Economic Growth. In order to analyze the contribution of E-commerce to economic growth, the E-commerce index was added into the Cobb-Douglas production 
function as an input factor of economic growth, and Cobb-Douglas was formed with the E-commerce index. The production function model has the following form:

$$
\mathrm{Y}=\mathrm{AE}^{\mathrm{e}} \mathrm{K}^{\mathrm{a}} \mathrm{L}^{\beta} \mathrm{e}^{\mathrm{u}}
$$

Among them, $\mathrm{Y}$ is the gross domestic product (GDP). K, $\mathrm{L}$ are the input of capital and labor factors; $\mathrm{E}$ is the E-commerce development index; e, $\alpha, \beta$ are the output elasticity respectively; $\mathrm{e}^{\mathrm{u}}$ is the random disturbance item. Take the logarithm of both sides of (1) to get:

$\mathrm{Ln} \mathrm{Y}=\ln \mathrm{A}+\mathrm{e} \ln \mathrm{E}+\alpha \ln \mathrm{K}+\beta \ln \mathrm{L}+\mathrm{u}$

In order to make input factors comparable, the labor and capital input from 2000 to 2009 were also converted into indices based on the same period in 2000. The regression analysis of the model using SPSS software yields:

$\mathrm{Ln} \mathrm{Y}=1.332+0.017 \ln \mathrm{E}+0.492 \ln \mathrm{K}+0.203 \ln \mathrm{L}+\mathrm{u}$

where $\mathrm{R}^{2}=0.998$, Adjusted $\mathrm{R}^{2}=0.997, \mathrm{~F}=965.136$

From the estimation results, the correction coefficient $R^{2}=0.997$, which is the logarithm of the total deviation of GDP, can be explained by $\operatorname{lnE}, \ln K, \ln L$, indicating that the model fits well. The model passed the $\mathrm{F}$ test. It can be seen that the results of this model are credible.

\section{Empirical Results and Econometric Analysis.}

According to the regression model (3), we can get the following results:

(1) During the period from 2000 to $2009,1 \%$ increase in Gansu E-commerce index will drive GDP growth $0.17 \%$, and the magnitude of the impact is increasing. It can be seen that the E-commerce factor has become the driving force for the growth of Gansu's GDP, and it is also a new growth point and engine for Gansu's economic development.

(2) The regression coefficient 0.017 of the E-commerce index is still far less than the capital factor 0.492 and the labor factor 0.203 .

The main driving force behind the rapid economic growth in Gansu is still the input of capital and labor. It also shows that the task of changing the economic development mode of Gansu is very heavy. E-commerce is a strategic emerging industry. It breaks through the most advanced Internet information technology.

Based on the large-scale development needs, it has significant leading and leading roles in the overall economic and social development of Gansu Province and long-term development. It is characterized by the concentration of knowledge and technology, low consumption of material resources, large growth potential, and good comprehensive benefits. We must pay great attention to E-commerce as the representative, including various forms of Internet economic models such as instant messaging, search engines, online games, and online advertising, to promote these emerging industries to play a greater role in economic development.

(3) The contribution of E-commerce in Gansu to the development of the national economy is about $0.017 \%$, which is a large difference from the forecast of the impact of E-commerce on GDP growth in developed countries. The main reason is that Gansu is still in the early stage of industrialization. Economic development mainly depends on the real economy. The main investment direction has not yet shifted to the service industry. In particular, the development of E-commerce is relatively slow, and its contribution to the growth of the national economy is still very small. This is a question that Gansu needs to attach great importance to during the development of the "Twelfth Five-Year Plan".

\section{Conclusions and Suggestions}

As an underdeveloped region, Gansu Province regards the development of E-commerce as an effective means to promote and accelerate economic and social development as an innovation of the government that conforms to the trend of economic and social development. Through empirical research on the development of electronic commerce in 14 cities of Gansu, the author believes that the development of electronic commerce in the western region should proceed from these aspects. The government strengthens organizational leadership and makes every effort to promote E-commerce development. It is necessary to establish a specialized agency that promotes the development of E-commerce, and the principal leaders are responsible persons. There are some misunderstandings in the development of 
E-commerce by the public. The government must actively intervene in order to guide the public to update their ideological awareness, and to popularize E-commerce related technologies and knowledge through training institutions. Efforts must be made to eliminate between East and West. In the transition to E-commerce companies, new modes and new formats should be actively explored in new areas such as rural E-commerce, manufacturing E-commerce, and cross-border E-commerce to promote innovation through innovation and strive to maintain rapid growth. Using a variety of media, extensive publicity campaigns were carried out to raise awareness of the necessity and urgency of E-commerce development among all sectors of the society, enhance the awareness of E-commerce applications among enterprises and citizens, and strive to create a favorable atmosphere for the development of E-commerce.

\section{Acknowledgements}

This work was supported by the Modernization and Social Harmonious Development in Ethnic Regions: Research and Innovation Team of Northwest Minzu University (Grant No: 31920180101) and by the Key Laboratory of E-commerce of Ethnic information in Gansu Provincial (Grant No:MDS2017001) and Comprehensive experimental teaching center in Economics (Grant No. 2016XJSYJXSF2X-01-10019109).

\section{References}

[1]Zheng Yaqin, Principal component cluster analysis of the development level of China's rural E-commerce regional infrastructure, Chinese Science and Technology Theory, 3 (2017) 20-27.

[2]Liu Ke, Analysis of Rural E-commerce Development, Economic System Reform, 4 (2015) 120-127.

[3]Zhou Haiqin, Key Factors for the Development of Electronic Commerce in China's Rural Areas, China Information, 3 (2008) 200-211.

[4] Yue Yunkang, Discussion on the development of new models of rural E-commerce, Agricultural Network Information, 12(2008) 87-89.

[5]Wei Wei, Zhong Yi, E-Commercialization, the Next Export of New Media, China Media \& Technology, 5 (2014)38-39.

[6]Wang Xixuan, The Application of Internet in Rural Northwest China: A Case Study of the Yellow Sheep River Model, NewWen University, 1(2006)61-65.

[7]Qi Yang, Changes and Influencing Factors of Rural Information Transmission in Western New Media: A Case Study of Rural Areas in Southern Shaanxi, Journal of Economic Research, 4 (2012)60-71.

[8]Zhou Guoqing, Demand Characteristics of Peasants' Audience and Countermeasures in New Media Environment, Hunan Normal University Journal of Social Science, 4 (2011)129-134.

[9]Li Weihua, New Media Development and New Chen Xie of Agricultural Society, Henan University School of Science, 5 (2011)132-136.

[10] Gao Chong, Intergenerational communication of rural youth in transitional communities in the context of new media, China Youth University for Political Studies, 2 (2012)24-28. 